\title{
Internet-Based Heat Evaluation and Assessment Tool (I-HEAT): Development of a Novel Visualization and Decision- support Tool for Extreme Heat Preparedness in Detroit, Michigan
}

\author{
KATHRYN C. CONLON ${ }^{1 *}$, NATALIE SAMPSON ${ }^{2}$, ROBERT ROMMEL $^{3}$, \\ GEOFFREY JACQUEZ ${ }^{3,4}$, MARIE S. O'NEILL ${ }^{5}$ \\ Volume 2, Fall 2014
}

http://dx.doi.org/10.3998/mjs.12333712.0002.007

${ }^{1}$ National Center for Atmospheric Research, PO Box 3000, Boulder CO 80307

2Department of Health and Human Services, University of Michigan School-Dearborn,

D9 Fairlane Center South 19000 Hubbard Drive, Dearborn, MI 48126

${ }^{3}$ BioMedware, 121 West Washington, Ann Arbor, MI 48104

${ }^{4}$ Department of Geography, 112 Wilkeson Hall, State University of New York at Buffalo,

Buffalo, New York 14261

${ }^{5}$ Departments of Environmental Health Sciences and Epidemiology, University of

Michigan School of Public Health, 1415 Washington Heights, Ann Arbor, MI 48109

${ }^{*}$ Corresponding author: Kathryn C. Conlon, kconlon@ucar.edu

Global mean temperatures are projected to rise $2-4^{\circ} \mathrm{F}$ by the mid twenty-first century (Kirtman et al. 2013) and are expected to be accompanied by more severe and longer periods of extreme heat in particular geographic locations, including regions in the United States. (Meehl and Tebaldi 2004). Extensive research on the adverse health effects of extreme heat exposure (Anderson and Bell 2011, Michelozzi et al. 2009, Anderson et al. 2013) contribute to focused efforts to reduce exposure via mitigation and adaptation (MCHP 2012, Hess, Schramm, and Luber 2014, Luber et al. 2014, Stone et al. 2013, Seroka, Kaiser, and Heany 2011). Efforts such as modifying built environments to reduce ambient temperatures (Stone et al. 2013) and increasing outreach to at-risk populations (Tompkins and Adger 2004) can help ensure healthy, sustainable urban systems. We sought to develop a user-friendly prototype tool that displays where heat-related vulnerability and land surface tem- 
perature coincide across Detroit, Michigan. We present the methods and technological infrastructure used to develop the Internet-based Heat Evaluation and Assessment Tool (I-HEAT).

Heat-related vulnerability is complex; it is influenced by environmental factors (Medina-Ramon and Schwartz 2007), demographic factors (Ostro et al. 2009, Semenza et al. 1996), and health and societal characteristics (Basu and Ostro 2008, Basu, Dominici, and Samet 2005, Schwartz 2005). Heat vulnerability indices (HVIs) are often mapped to display spatial patterns of vulnerability (Harlan et al. 2013, Reid et al. 2009, Johnson et al. 2012). Following Reid et al. (2009), we calculated and mapped an HVI comprised of individual- and community-level characteristics that contribute to heat-related vulnerability (Reid et al. 2012). Data were obtained from the 2000 U.S. Census (www.census.gov) and aggregated at the census tract level. Variables included proportions of the population over the age of 65 , living alone, over the age of 65 and living alone, living below poverty, non-white, and without a high school education. The index also considered the prevalence of air conditioning and diabetes among elderly people. I-HEAT contains a section displaying Landsat 5 satellite imagery. The imagery was converted to land surface temperature and the Normalized Difference Vegetation Index (NDVI), which capture the contribution of local land cover to surface temperature. Satellite-derived land surface temperature is a reliable measurement of exposure to heat in Detroit (White-Newsome et al. 2013). We calculated brightness temperature using Band 6 (low gain) via the algorithms of Chander, Markham, and Helder (2009), and we used Bands 3 (red visible) and 4 (near infrared) to calculate the NDVI. We used a simple model to estimate heat-related risk $(R)$ modeled as a function of exposure and vulnerability factors in I-HEAT:

$$
R=(1-\mathrm{x}) V+\mathrm{x} T,
$$

where $\mathrm{x}$ is the user-defined relative weight, $V$ is the standardized HVI and $T^{\prime}$ is the standardized land surface temperature at a specific location. I-HEAT users can specify relative weights for exposure and vulnerability. The risk is linearly scaled, and the areas of highest risk appear in red on the map. A slider feature allows the user to dynamically adjust the relative strength of the two factors. I-HEAT is accessible at http://www.biomedware.com/I-Heat/IHeatViewer.html.

The I-HEAT software targets non-technical users who require user-friendly, easily accessible tools that can host geospatial data (e.g., satellite imagery). Traditional geographic information systems (GIS) are limited in their ability to represent complex 
spatio-temporal relationships (Jacquez, Maruca, and Fortin 2000). The infrastructure is based on the Space-Time Intelligence Software (STIS) technology that was developed to suit the representation, visualization and analysis of spatial patterns and processes (Jacquez 2009); it also allows for user-customized secure, inexpensive data storage (Carter 2007). I-HEAT runs in any Adobe Flash-supported web browser and can easily be updated to accommodate changing Internet technology.

In creating the I-HEAT, we were limited to available data. Satellite images often required additional post-processing (e.g., gap-filled products), and images from a cloudless day during the summer months (May-September) were scarce. The Landsat 5 imagery used in the I-HEAT prototype was taken on September 1, 2002 (Path 20, Rows 30-31) (http://glovis.usgs.gov). We chose to construct the HVI using 2000 census demographic and health data to maintain temporal consistency with the satellite imagery. Like many prototypes, the tool could be greatly enhanced by numerous updates. At the time of development, Landsat 8 data were not available. Future versions of I-HEAT will utilize Landsat 8 imagery, 2010 census data, and meteorological models that better characterize local temperature. Alternative calculations of heat vulnerability could include variables beyond those in Reid et al. (2009), specifically those accounting for adaptive capacity (Luers et al. 2003, Tate 2012, Harlan et al. 2013). Furthermore, estimated heat-related risk $(R)$ could include an adaptive capacity indicator term to account for activities that explicitly increase adaptive capacity, such as community-specific efforts to increase education and outreach in elderly populations on the warning signs of heat-related illness, which are commonly misunderstood or ignored in older populations (Sampson et al. 2013). Thus, increasing adaptive capacity by altering the knowledge, attitudes and practices pertaining to heat-related illness would contribute to a lower risk.

Although I-HEAT is specific to Detroit, Michigan, the methodology and technology used in its development can be replicated and implemented by many communities and sectors. It follows a main tenet of sustainability frameworks as it is rooted in translating high-quality research findings into products that can assist in decision making related to natural and human systems (Tàbara and Chabay 2013). Future versions of I-HEAT could incorporate user-controlled input data that reflect local knowledge, tailoring the mapping output to the needs of the user. An I-HEAT feasibility analysis, presented in Sampson et al. (2014), resulted in a tool update that added Detroit cooling center locations. The addition provided a visual, researchderived product that public health practitioners can use to determine areas in the City where vulnerability is high and cooling center access is limited. I-HEAT applications extend to urban planning, civil engineering, and education. Planners could 
use the NDVI imagery in concert with vulnerability and land surface temperature estimates to identify where vegetation could be increased, ultimately reducing ambient air temperature (Stone et al. 2013) and increasing sustainability by reducing the amount of water and energy required to cool living spaces. Often, recommendations for reducing exposure to extreme heat involve the use of energy-intensive cooling devices (e.g., air conditioning), which, over time, contribute to a further increase in local and global temperatures (Salamanca et al. 2014). Geospatial tools like I-HEAT can play a critical role in communicating how environmental and human health are intertwined, ultimately informing co-beneficial actions that ensure the sustainability of both natural and human systems.

\section{References}

Anderson, G Brooke, and Michelle L Bell. 2011. "Heat waves in the United States: mortality risk during heat waves and effect modification by heat wave characteristics in 43 U.S. communities." Environ Health Perspect 119 (2):210-8. doi: 10.1289/ehp.1002313.

Anderson, G. Brooke, Francesca Dominici, Yun Wang, Meredith C. McCormack, Michelle L. Bell, and Roger D. Peng. 2013. "Heat-related Emergency Hospitalizations for Respiratory Diseases in the Medicare Population." American Journal of Respiratory and Critical Care Medicine 187 (10):1098-1103. doi: 10.1164/rccm.201211-1969OC.

Basu, Rupa, Francesca Dominici, and Jonathan M Samet. 2005. "Temperature and Mortality Among the Elderly in the United States.” Epidemiology 16 (1):58-66. doi: 10.1097/01. ede.0000147117.88386.fe.

Basu, Rupa, and Bart D. Ostro. 2008. "A Multicounty Analysis Identifying the Populations Vulnerable to Mortality Associated with High Ambient Temperature in California." American Journal of Epidemiology 168 (6):632-637. doi: 10.1093/aje/kwn170.

Carter, S. 2007. “The new language of business: SOA \& Web 2.0.” 299.

Chander, Gyanesh, Brian L. Markham, and Dennis L. Helder. 2009. "Summary of current radiometric calibration coefficients for Landsat MSS, TM, ETM+, and EO-1 ALI sensors." Remote Sensing of Environment 113 (5):893-903. doi: http://dx.doi.org/10.1016/j.rse.2009.01.007.

Harlan, S. L., J. H. Declet-Barreto, W. L. Stefanov, and D. B. Petitti. 2013. "Neighborhood effects on heat deaths: social and environmental predictors of vulnerability in Maricopa County, Arizona." Environmental Health Perspectives 121 (2):197-204. doi: 10.1289/ehp.1104625.

Hess, Jeremy J., Paul J. Schramm, and George Luber. 2014. "Public Health and Climate Change Adaptation at the Federal Level: One Agency's Response to Executive Order 13514." American Journal of Public Health 104 (3):e22-e30. doi: 10.2105/AJPH.2013.301796.

Jacquez, G. M., S. Maruca, and M. J. Fortin. 2000. "From fields to objects: A review of geographic boundary analysis.” Journal of Geographical Systems 2 (3):221-241. doi: 10.1007/PL00011456.

Jacquez, GM. 2009. "Space-Time Intelligence System Software for the Analysis of Complex Systems." In Handbook of Applied Spatial Analysis: Software Tools, Methods and Applications, edited by Getis A Fischer M. Springer. 
Johnson, Daniel P., Austin Stanforth, Vijay Lulla, and George Luber. 2012. "Developing an applied extreme heat vulnerability index utilizing socioeconomic and environmental data." Applied Geography 35 (1,Äì):23-31. doi: http://dx.doi.org/10.1016/j.apgeog.2012.04.006.

Kirtman, B, SB Power, JA Adedoyin, GJ Boer, R Bojar, I Camilloni, FJ Doblas-Reyes, AM Fiore, M Kimoto, GA Meehl, M Prather, A Sarr, C Schar, R Sutton, GJ van Oldenborgh, G Vecchi, and HJ Wang. 2013. Near-term climate change: Projections and predictability. In Climate Change 2013: The Physical Science Basis. Contribution of Working Group I to the Fifth Assessment Report of the Intergovernmental Panel on Climate Change, edited by TF Stocker, D Qin, GK Platter, M Tignor, SK Allen, J Boschung, A Nauels, Y Xia and PM Midgley. United Kingdom and New York, NY USA.

Luber, G, K Knowlton, J Balbus, H Frumkin, M Hayden, J Hess, M McGeehin, N Sheats, L Backer, B Beard, K L Ebi, E Maibach, RS Ostfeld, C Weidinmyer, E ZIelinski-Gutierrez, and L Ziska. 2014. Ch. 9: Human Health. In Climate Change Impacts in the United States: The Third National Climate Assessment, edited by JM Melillo, T Richmond and GW Yohe.

Luers, Amy L., David B. Lobell, Leonard S. Sklar, C. Lee Addams, and Pamela A. Matson. 2003. "A method for quantifying vulnerability, applied to the agricultural system of the Yaqui Valley, Mexico." Global Environmental Change 13 (4):255-267. doi: http://dx.doi.org/10.1016/ S0959-3780(03)00054-2.

Minnesota Climate and Health Program. 2012. Minnesota Extreme Heat Toolkit. edited by Minnesota Climate and Health Program. St. Paul, MN.

Medina-Ramon, M, and J Schwartz. 2007. "Temperature, temperature extremes, and mortality: a study of acclimatisation and effect modification in 50 US cities." Occupational and Environmental Medicine 64 (12):827-33.

Meehl, Gerald A, and Claudia Tebaldi. 2004. "More intense, more frequent, and longer lasting heat waves in the 21st century." Science 305 (5686):994-7. doi: 10.1126/science.1098704.

Michelozzi, P, G Accetta, M De Sario, D D'ippoliti, C Marino, M Baccini, A Biggeri, H. R Anderson, K Katsouyanni, F Ballester, L Bisanti, E Cadum, B Forsberg, F Forastiere, P. G Goodman, A Hojs, U Kirchmayer, S Medina, A Paldy, C Schindler, J Sunyer, and C. A Perucci. 2009. "High Temperature and Hospitalizations for Cardiovascular and Respiratory Causes in 12 European Cities." Am J Respir Crit Care Med 179 (5):383-389. doi: 10.1164/rccm.200802217OC.

Ostro, Bart D., Lindsey A. Roth, Rochelle S. Green, and Rupa Basu. 2009. "Estimating the mortality effect of the July 2006 California heat wave." Environmental Research 109 (5):614-619. doi: http://dx.doi.org/10.1016/j.envres.2009.03.010.

Reid, Colleen E, Marie S O’Neill, Carina J Gronlund, Shannon J Brines, Daniel G Brown, Ana V Diez-Roux, and Joel Schwartz. 2009. "Mapping community determinants of heat vulnerability.” Environ Health Perspect 117 (11):1730-6. doi: 10.1289/ehp.0900683.

Reid, Colleen E., Jennifer K. Mann, Ruth Alfasso, Paul B. English, Galatea C. King, Rebecca A. Lincoln, Helene G. Margolis, Dan J. Rubado, Joseph E. Sabato, Nancy L. West, Brian Woods, Kathleen M. Navarro, and John R. Balmes. 2012. "Evaluation of a Heat Vulnerability Index on Abnormally Hot Days: An Environmental Public Health Tracking Study." Environ Health Perspect 120 (5).

Salamanca, F., M. Georgescu, A. Mahalov, M. Moustaoui, and M. Wang. 2014. "Anthropogenic heating of the urban environment due to air conditioning." Journal of Geophysical Research: Atmospheres:2013JD021225. doi: 10.1002/2013JD021225. 
Sampson, Natalie R., Carina J. Gronlund, Miatta A. Buxton, Linda Catalano, Jalonne L. WhiteNewsome, Kathryn C. Conlon, Marie S. O’Neill, Sabrina McCormick, and Edith A. Parker. 2013. "Staying cool in a changing climate: Reaching vulnerable populations during heat events." Global Environmental Change 23 (2):475-484. doi: http://dx.doi.org/10.1016/j. gloenvcha.2012.12.011.

Sampson, NR, KC Conlon, R Rommel, G Jacquez, and MS O’Neill. 2014. “Internet-Based Heat Evaluation and Assessment Tool (I-HEAT): Feasibility analysis of a visualization and decisionsupport tool for extreme heat preparedness in Detroit, Michigan." Michigan Journal of Sustainability In Press.

Schwartz, Joel. 2005. "Who is sensitive to extremes of temperature?: A case-only analysis." Epidemiology $16(1): 67-72$.

Semenza, J C, C H Rubin, K H Falter, J D Selanikio, W D Flanders, H L Howe, and J L Wilhelm. 1996. "Heat-related deaths during the July 1995 heat wave in Chicago." N Engl J Med 335 (2):84-90. doi: 10.1056/NEJM199607113350203.

Seroka, C, P Kaiser, and J Heany. 2011. Mapping Heat Vulnerability in Michigan. In MPHI Annual Report, edited by Michigan Public Health Institute.

Stone, Brian, Jason Vargo, Peng Liu, Yongtao Hu, and Armistead Russell. 2013. "Climate Change Adaptation Through Urban Heat Management in Atlanta, Georgia.” Environmental science \& technology 47 (14):7780-7786. doi: 10.1021/es304352e.

Tàbara, J. David, and Ilan Chabay. 2013. "Coupling Human Information and Knowledge Systems with social-ecological systems change: Reframing research, education, and policy for sustainability." Environmental Science \& Policy 28 (0):71-81. doi: http://dx.doi.org/10.1016/j. envsci.2012.11.005.

Tate, Eric. 2012. "Social vulnerability indices: a comparative assessment using uncertainty and sensitivity analysis." Natural Hazards 63 (2):325-347. doi: 10.1007/s1 1069-012-0152-2.

Tompkins, EL, and W. N Adger. 2004. "Does adaptive management of natural resources enhance resilience to climate change?" Ecology and Society 9 (2). doi: http://www.ecologyandsociety.org/ vol9/iss2/art10.

White-Newsome, Jalonne L., Shannon J Brines, Daniel GD Brown, JT Dvonch, Carina J Gronlund, Kai Zhang, Evan M. Oswald, and M S O'neill. 2013. "Validating satellite-derived land surface temperature with in situ measurements: A public health perspective "Environmental Health Perspectives. doi: doi:10.1289/ehp.1206176. 